NASA/TM-2012-217639

\title{
Heated-Atmosphere Airship for the Titan Environment: Thermal Analysis
}

R.S. Heller

Massachusetts Institute of Technology, Cambridge, Massachusetts

G.A. Landis and A.F. Hepp

Glenn Research Center, Cleveland, Ohio

A.J. Colozza

QinetiQ North America Corporation, Cleveland, Ohio 


\section{NASA STI Program . . . in Profile}

Since its founding, NASA has been dedicated to the advancement of aeronautics and space science. The NASA Scientific and Technical Information (STI) program plays a key part in helping NASA maintain this important role.

The NASA STI Program operates under the auspices of the Agency Chief Information Officer. It collects, organizes, provides for archiving, and disseminates NASA's STI. The NASA STI program provides access to the NASA Aeronautics and Space Database and its public interface, the NASA Technical Reports Server, thus providing one of the largest collections of aeronautical and space science STI in the world. Results are published in both non-NASA channels and by NASA in the NASA STI Report Series, which includes the following report types:

- TECHNICAL PUBLICATION. Reports of completed research or a major significant phase of research that present the results of NASA programs and include extensive data or theoretical analysis. Includes compilations of significant scientific and technical data and information deemed to be of continuing reference value. NASA counterpart of peer-reviewed formal professional papers but has less stringent limitations on manuscript length and extent of graphic presentations.

- TECHNICAL MEMORANDUM. Scientific and technical findings that are preliminary or of specialized interest, e.g., quick release reports, working papers, and bibliographies that contain minimal annotation. Does not contain extensive analysis.

- CONTRACTOR REPORT. Scientific and technical findings by NASA-sponsored contractors and grantees.
- CONFERENCE PUBLICATION. Collected papers from scientific and technical conferences, symposia, seminars, or other meetings sponsored or cosponsored by NASA.

- SPECIAL PUBLICATION. Scientific, technical, or historical information from NASA programs, projects, and missions, often concerned with subjects having substantial public interest.

- TECHNICAL TRANSLATION. Englishlanguage translations of foreign scientific and technical material pertinent to NASA's mission.

Specialized services also include creating custom thesauri, building customized databases, organizing and publishing research results.

For more information about the NASA STI program, see the following:

- Access the NASA STI program home page at http://www.sti.nasa.gov

- E-mail your question to help@sti.nasa.gov

- Fax your question to the NASA STI Information Desk at 443-757-5803

- Phone the NASA STI Information Desk at 443-757-5802

- Write to: STI Information Desk NASA Center for AeroSpace Information 7115 Standard Drive Hanover, MD 21076-1320 
NASA/TM-2012-217639

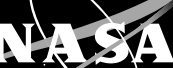

Heated-Atmosphere Airship for the Titan Environment: Thermal Analysis

\section{R.S. Heller}

Massachusetts Institute of Technology, Cambridge, Massachusetts

G.A. Landis and A.F. Hepp

Glenn Research Center, Cleveland, Ohio

\section{A.J. Colozza}

QinetiQ North America Corporation, Cleveland, Ohio

Prepared for the

Earth and Space 2012 Conference

sponsored by the American Society of Civil Engineers

Pasadena, California, April 15-18, 2012

National Aeronautics and

Space Administration

Glenn Research Center

Cleveland, Ohio 44135 
This report contains preliminary findings, subject to revision as analysis proceeds.

Trade names and trademarks are used in this report for identification only. Their usage does not constitute an official endorsement, either expressed or implied, by the National Aeronautics and Space Administration.

Level of Review: This material has been technically reviewed by technical management.

Available from

NASA Center for Aerospace Information 7115 Standard Drive

Hanover, MD 21076-1320
National Technical Information Service 5301 Shawnee Road Alexandria, VA 22312

Available electronically at http://www.sti.nasa.gov 


\title{
Heated-Atmosphere Airship for the Titan Environment: Thermal Analysis
}

\author{
R.S. Heller \\ Massachusetts Institute of Technology \\ Cambridge, Massachusetts 02139 \\ G.A. Landis and A.F. Hepp \\ National Aeronautics and Space Administration \\ Glenn Research Center \\ Cleveland, Ohio 44135 \\ A.J. Colozza \\ QinetiQ North America Corporation \\ Cleveland, Ohio 44135
}

\begin{abstract}
Future exploration of Saturn's moon Titan can be carried out by airships. Several lighter-thanatmosphere gas airships and passive drifting heated-atmosphere balloon designs have been studied, but a heated-atmosphere airship could combine the best characteristics of both. This work analyses the thermal design of such a heated-atmosphere vehicle, and compares the result with a lighter-than-atmosphere (hydrogen) airship design. A design tool was created to enable iteration through different design parameters of a heated-atmosphere airship (diameter, number of layers, and insulating gas pocket thicknesses) and evaluate the feasibility of the resulting airship. A baseline heated-atmosphere airship was designed to have a diameter of $6 \mathrm{~m}$ (outer diameter of $6.2 \mathrm{~m}$ ), three-layers of material, and an insulating gas pocket thickness of $0.05 \mathrm{~m}$ between each layer. The heated-atmosphere airship has a mass of $161.9 \mathrm{~kg}$. A similar mission making use of a hydrogen-filled airship would require a diameter of $4.3 \mathrm{~m}$ and a mass of about $200 \mathrm{~kg}$. For a long-duration mission, the heated-atmosphere airship appears better suited. However, for a mission lifetime under 180 days, the less complex hydrogen airship would likely be a better option.
\end{abstract}

\section{Introduction}

Titan, the largest moon in the solar system, and the only moon with an atmosphere, is a high priority target for future science missions. The Cassini mission to Saturn landed a probe, Huygens, on the surface of Titan, but this probe only had a short lifetime on the surface, and had no mobility after landing. Future missions to Titan are desired with the capability to explore the nature of the moon and its environment in greater detail.

Several options have been considered as follow-on to the Huygens-Cassini mission. Of these, the main consideration for a Titan mission has been the type of vehicle used to collect data. A follow-on joint proposal between National Aeronautics and Space Administration (NASA) and European Space Agency (ESA) has mentioned three desired vehicles. One was an orbiter similar to the Cassini orbiter. Another was a lake lander similar to Huygens, but with the emphasis of studying a lake instead of the atmosphere. The final vehicle was an atmospheric balloon. This proposed mission was called the Titan Saturn System Mission (TSSM) (TSSM 2009). The TSSM atmospheric balloon was planned to passively collect atmospheric data at an altitude of about $10 \mathrm{~km}$. The power source of the electronics as well as the heat source for the balloon would come from a Radioisotope Thermoelectric Generator (RTG) (TSSM 2009). However, the TSSM would not be well suited to study the organic molecules that have accumulated around the moon. This has led to proposals to use controlled aerial vehicles that could move around the moon and land at various sites to collect samples. Several types of aerial vehicles could be used. These include: balloons, airships, vertical takeoff, and landing vehicles (such as helicopters), airplanes, gliders, and rockets. 


\section{Previous Work}

Two earlier studies (Colozza et al. (Colozza 2003) and Lorenz (Lorenz 2000a)) compared different aerial vehicles for use on Titan. Wright et al. (Wright 2004) concluded that airships are the best for initial missions, with vertical takeoff and landing vehicles being considered for future missions due to the improved landing and takeoff ability. Lorenz et al. (Lorenz 2005) proposed an airship that would float and act as a balloon if propulsion were to fail either permanently or temporarily, providing an inherent redundancy to the flight capability for the mission. Designs for airplanes and vertical takeoff and landing vehicles would not have this capability, and hence failure of the propulsion system would likely be mission ending. Lorenz (Lorenz 2000a) considered a reference concept of a vertical takeoff and landing vehicle, selected for ease of landing at desired sites. Of these two design possibilities, the airship was the vehicle type analyzed in this report.

Airships are very similar to balloons, but instead of passively relying on winds to move (such as winds used for drift discussed in Lorenz et al. (Lorenz 2010)), they have an active propulsion system. Various airship designs are also commonly referred to as dirigibles, Zeppelins, and blimps. They could either use lighter-than-atmosphere gas or heated-atmosphere for lift. Studies have been conducted to understand the performance of Titan airships using lighter-than-atmosphere gas as the lifting gas. A paper by Duffner et al. (Duffner 2007) analyzes a hydrogen gas airship with a rover appendage for surface studies. Lorenz (Lorenz 2000b) discussed how an airship could maintain continuous flight with dutycycled propellers for conserved power propulsion. The paper suggested that the surface could be studied by drop sondes, or by possibly landing the airship. Elfes et al. (Elfes 2005) and the ESA Titan Saturn System Mission report (TSSM 2009) proposed that excess heat from an RTG could be used for lift. Duffner et al. (Duffner 2007), Lorenz (Lorenz 2000b), and Wright et al. (Wright 2004) required an RTG for the electrical power needs. Additionally, the TSSM planned to use an RTG heated-atmosphere balloon; however, an RTG heated-atmosphere airship could make use of the waste heat of an RTG, saving launch weight by providing the initial lifting gas. It would also have the maneuverability of an airship for possibly greater science return.

The material for the lifting gas envelope is also an important consideration. This is due to the atmospheric conditions as well as the necessary constraints for a working airship. The material must be nonporous, foldable for storage to Titan, resistant to tearing, and maintain these properties at cryogenic temperatures. Hall et al. (Hall 2008) proposed a combination of polyester and Mylar for an effective cryogenic balloon material. Their paper demonstrated that this material satisfactorily meets the necessary criteria discussed.

\section{Radioisotope Generator}

A Radioisotope Thermoelectric Generator (RTG), uses a nuclear isotope heat source and a thermoelectric (thermal-to-electrical) transducer to convert heat produced from radioactive decay to electricity. A commonly used fuel is $\mathrm{Pu}^{238}$, which has a half-life of about 87 years, and therefore can support a mission for several decades. The plutonium is packaged into a standard general purpose heat source (GPHS) block for use in spacecraft applications. Each block produces $250 \mathrm{~W}$ of thermal power at its beginning of life and has a mass of $1.44 \mathrm{~kg}$. The primary disadvantage of implementing RTGs is the low level of electrical power that they supply. Large power requirements would necessitate many RTG units, which would consequently increase the system's complexity, mass and cost. RTGs have been used in many space vehicles and satellites such as the Voyager spacecraft discussed in Freedman et al. (Freedman 1966). This demonstrates that RTGs are a viable option so long as large power requirements are not needed. Higher-efficiencies can be achieved through the use of a dynamic conversion technique instead of a thermoelectric element, for example, a Stirling converter. This has been demonstrated in the form of the Advanced Stirling Radioisotope Generator (ASRG) (Wong 2008), which can achieve conversion efficiencies near 30 percent. 
For the following analysis the Multi-Mission Radioisotope Thermoelectric Generator (MMRTG) was assumed as the power and thermal source. This RTG is used on the Mars Science Laboratory. At the time of arrival at Titan, it will produce about $100 \mathrm{~W}$ of electrical power for about $1700 \mathrm{~W}$ of thermal power (TSSM 2009). The mass of the MMRTG along with a battery system is assumed to be $100 \mathrm{~kg}$.

\section{Buoyancy Calculations for Heated Gases}

A balloon or airship for operation on Titan achieves its lift by use of a confined envelope of gas that is lighter than the surrounding atmosphere. This can be achieved either by using a lifting gas of lower molecular weight than the ambient (optimally hydrogen), or by filling the envelope from the surrounding atmosphere and heating the interior gas to a higher temperature, thus reducing its density ("heated atmosphere"). The heated-atmosphere approach has the advantage of not requiring fill gas to be brought from Earth. Hence, it is relatively insensitive to the gas leakage rate, and can achieve long duration flight as long as a heat source is available, without replenishing the fill gas. However, the approach required the gas to be at a higher temperature than the surrounding atmosphere, and hence the lift achieved depends on the thermal design. This work is intended to calculate the thermal analysis of such a design, in order to compare the heated-atmosphere and lifting-gas approaches for lift in the Titan environment.

In order for an airship to float in an atmosphere, the buoyancy force must overcome the force of gravity. Buoyancy comes from the Archimedes principle that the weight of fluid displaced equals upward buoyancy force. Because the airship uses heated atmosphere, the density of the internal gas can be closely approximated from the ideal gas law. For the buoyancy calculation, we can approximate the airship as a sphere with internal diameter $D$, calculated from the sphere's volume. Thus, Equation (1) relates buoyancy to the mass of the airship, where $P$ is the gas pressure, $R_{s}$ is the specific gas constant $(\mathrm{J} / \mathrm{kgK})$, $T$ is the temperature of the gas, $\rho_{\text {atm }}$ is the density of the atmosphere, and $m$ is the total mass that can be lifted. In order for the vehicle to achieve flight, its mass must be equal to or less then this mass.

$$
m=\frac{D^{3} \pi}{6}\left(\rho_{\mathrm{atm}}-\frac{P}{R_{s} T}\right)
$$

\section{Thermal Balance}

The buoyancy (Eq. (1)), contains three unknown variables: the airship diameter, the average temperature inside the airship, and the mass that can be lifted. The pressure within the envelope $(P)$ is held near atmospheric pressure in order to minimize the stress on the envelope material. The relationship between the airship diameter and the average inside temperature is then calculated by analyzing the heat transfer from the warm environment inside of the airship to the colder environment of Titan's atmosphere. The heat source (from the MMRTG) provides a constant flux of waste heat to the gas within the envelope. The heat loss to the environment is proportional to the surface area of the gas envelope: the larger the diameter, the lower the inside temperature will be. Figure 1 shows the thermal circuit diagram for a three-layer example.

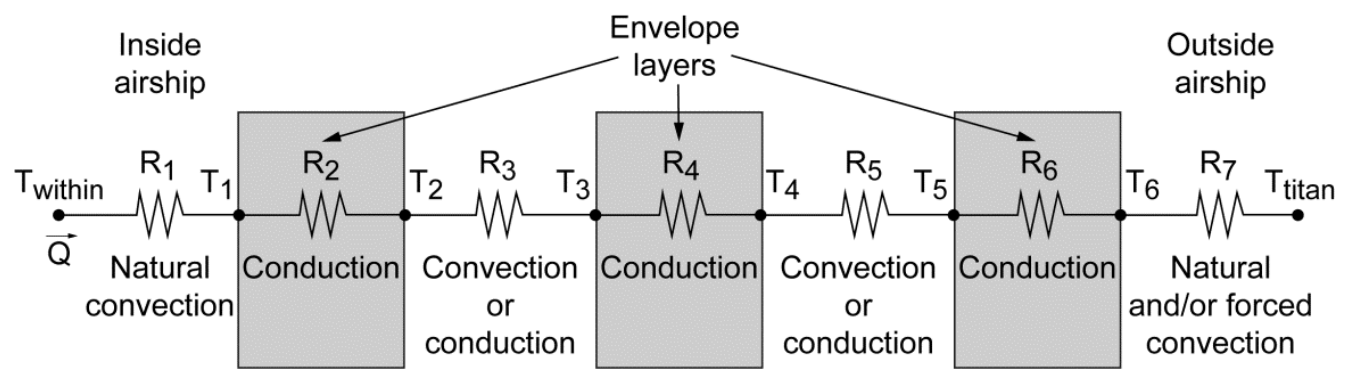

Figure 1.-Three-layer thermal circuit with identified methods of heat transfer. 
The equivalent thermal resistor for a three-layer airship is simply the sum of the resistors from Figure 1. The equation for the internal temperature is given by Equation (2), where $T_{w}$ is the temperature within the airship, and $T_{t}$ is the temperature of Titan's atmosphere.

$$
T_{w}=T_{t}+Q\left(R_{1}+R_{2}+R_{3}+R_{4}+R_{5}+R_{6}+R_{7}\right)
$$

The temperature of Titan's atmosphere is assumed to be $95 \mathrm{~K}$ and the thermal load $Q$ is an input variable set by the amount of isotope used in the MMRTG. The value of each of the thermal resistors must be determined. The thermal resistance for conduction through the material layers is given by Equation (3) and the thermal resistance for convection from the inner and outer surfaces is given by Equation (4), where $r_{o}$ is the outer radius, $r_{i}$ is the inner radius, and $r_{s}$ is the radius of the surface where convection is taking place.

$$
\begin{gathered}
R_{\text {cond }}=\frac{r_{o}-r_{i}}{4 \pi k r_{i} r_{o}} \\
R_{\text {conv }}=\frac{1}{4 \pi h r_{s}^{2}}
\end{gathered}
$$

Two quantities are needed to solve for the thermal resistance in the conduction case: the thickness of the material and thermal conductivity of the material. For the convection cases, only the heat transfer coefficient $(h)$ needs to be solved for.

\section{Iteration Program}

The effects of the three main design parameters (the diameter, number of layers, and the thickness of the insulating gas pockets) on the mass of the vehicle as well as the mass that can be lifted were evaluated. An iteration program was utilized since thermal resistance depends on the temperature, and the temperature affects the thermal resistance. Table 1 shows the assumed values and constants that were used in the iteration program.

The wind speed here is the relative speed difference between the airship and the actual wind velocity. For example, a completely unpowered airship would move with the wind and would have a relative wind speed of zero. A temperature of $95 \mathrm{~K}$ was assumed for the atmosphere, representative of the highest (i.e., worst case) atmospheric temperature. Since the lower the atmospheric temperature, the greater its density and therefore buoyancy force, operation at a lower temperature would result in the ability to carry a slightly higher payload mass.

TABLE 1.-CONSTANT PROPERTIES WITH ASSUMED VALUES

\begin{tabular}{|l|c|}
\hline \multicolumn{1}{|c|}{ Property } & Value \\
\hline Envelope material thickness & $0.00003 \mathrm{~m}$ \\
\hline Cryogenic envelope material weight (Hall 2008) & $94 \mathrm{~g} / \mathrm{m}^{2}$ \\
\hline Estimated thermal conductivity of the cryogenic envelope material & $0.4 \mathrm{~W} / \mathrm{mK}$ \\
\hline Titan pressure (Friedlander 1986) & $160 \mathrm{kPa}$ \\
\hline Titan gravity & $1.352 \mathrm{~m} / \mathrm{s}^{2}$ \\
\hline Titan temperature & $95 \mathrm{~K}$ \\
\hline Wind speed & $5 \mathrm{~m} / \mathrm{s}$ \\
\hline Specific gas constant for the atmospheric nitrogen & $297 \mathrm{~J} / \mathrm{kgK}$ \\
\hline RTG heat (TSSM 2009) & $1700 \mathrm{~W}$ \\
\hline Mass of RTG and Battery System (Duffner 2007) & $100 \mathrm{~kg}$ \\
\hline Mass of instruments (Duffner 2007) & $28.9 \mathrm{~kg}$ \\
\hline Prandlt number of atmosphere (TSSM 2009) & 0.796 \\
\hline
\end{tabular}




\section{Results}

A number of parameters, including diameter, insulating gas pocket thickness, and number of layers as well as the lifting mass, deadweight, and extra payload, can be adjusted to affect the design output. In order to narrow down the list of choices, consideration was given to difficulty. For an example, larger numbers of layers are more difficult to build, and a heavier deadweight means more fuel would be expended for launch. With these considerations in mind, a satisfactory set of feasible parameters was chosen for the baseline airship. The parameters are presented in Table 2.

Figures 2 and 3 show the effects of modifying the number of layers and the thickness of the insulating gas pocket between the layers, respectively. It is seen that there is a significant increase in payload mass (over $250 \mathrm{~kg}$ ) by adding two extra envelope layers compared to using a single layer, but with more additions, there is only a small increase in the payload mass. Figure 3 shows that, as the insulating gas pocket thickness increases, the payload mass increases. However, it should be noted that as the insulating gas pocket thickness increases, the outer diameter also increases.

The heated-atmosphere airship was designed primarily to interact with and explore the surface of Titan. As the airship's altitude increases, the payload mass capability diminishes until the airship reaches an altitude where neutral buoyancy takes place. From the surface to an altitude of $20 \mathrm{~km}$, both the temperature and the density of the atmosphere decrease approximately linearly. At the $20 \mathrm{~km}$ altitude, the temperature was estimated to be $78 \mathrm{~K}$ and the density of the atmosphere was estimated to be $2 \mathrm{~kg} / \mathrm{m}^{3}$ (Jennings 2011, Justus 2004). Figure 4 shows the effect that the operating altitude has on the payload for different internal diameters. The baseline airship with a diameter of $6 \mathrm{~m}$ would be able to reach a maximum altitude of $6 \mathrm{~km}$. Different designs would be required to reach higher altitudes, such as an airship with a larger diameter. An airship with an internal diameter of about $8 \mathrm{~m}$ is shown to have the highest payload mass at an altitude of $6 \mathrm{~km}$ (about $75 \mathrm{~kg}$ ). At $6 \mathrm{~km}$, the range of feasible airships with three-layers and an insulating gas pocket thickness of $0.05 \mathrm{~m}$ are those with an internal diameter between 5.2 and $10.1 \mathrm{~m}$.

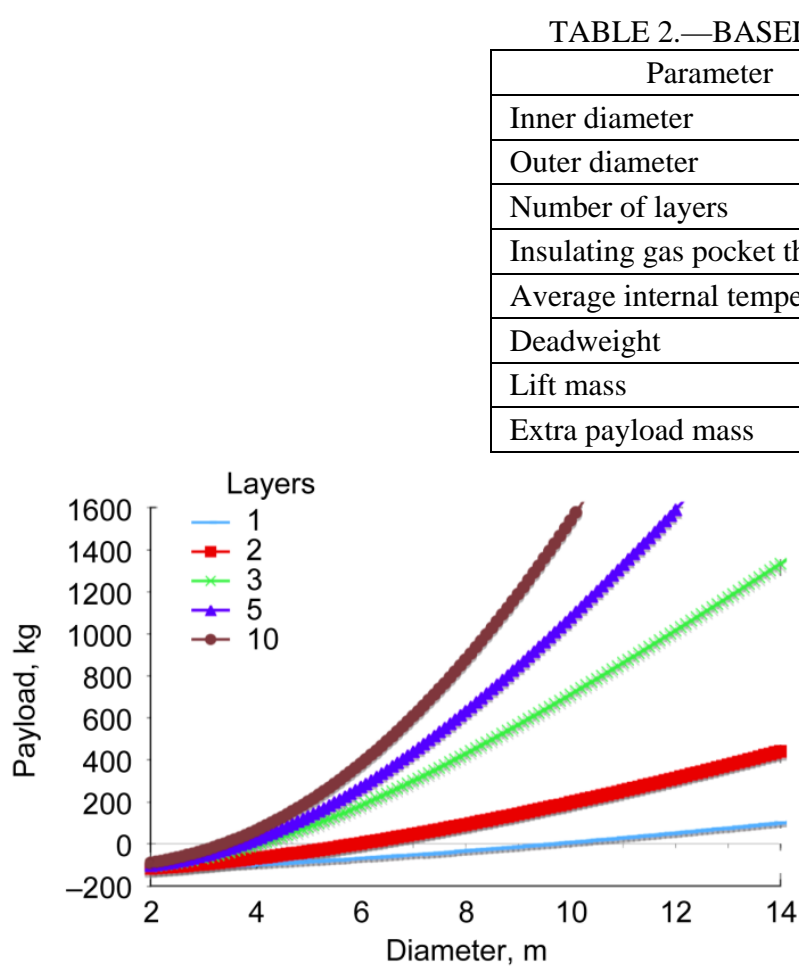

Figure 2.-Effect on airship payload sizing of number of layers and internal diameters, for an insulating gas pocket(s) of $0.05 \mathrm{~m}$ (when applicable). 


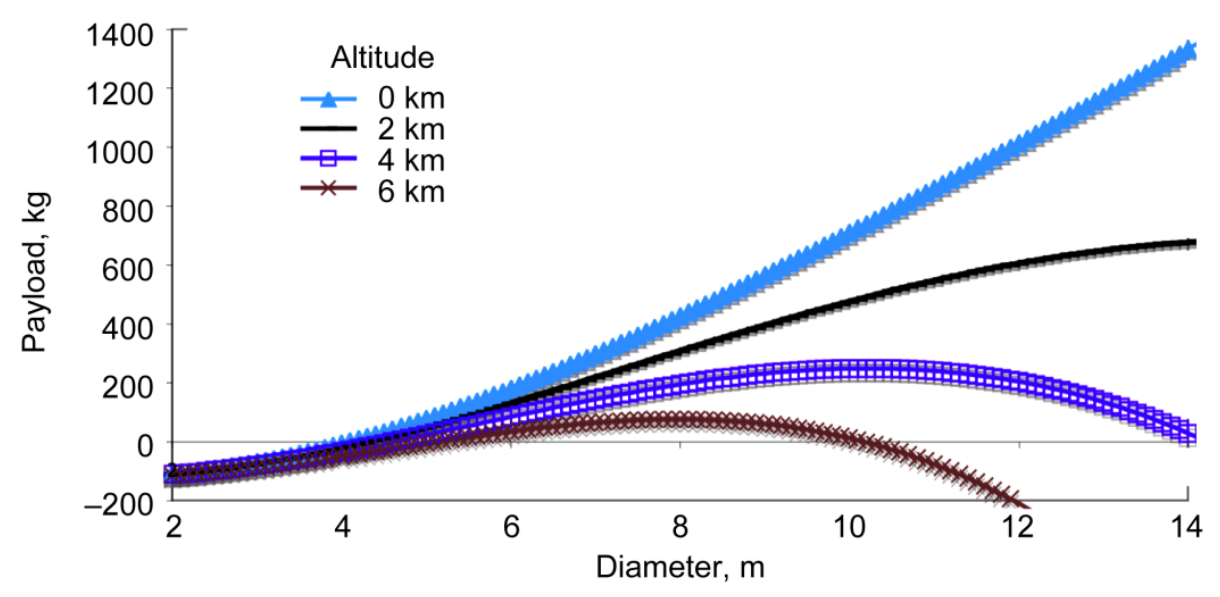

Figure 4.-Payload capability as a function of altitude for different internal diameters for baseline airship with three layers and an insulating gas pocket thickness of $0.05 \mathrm{~m}$.

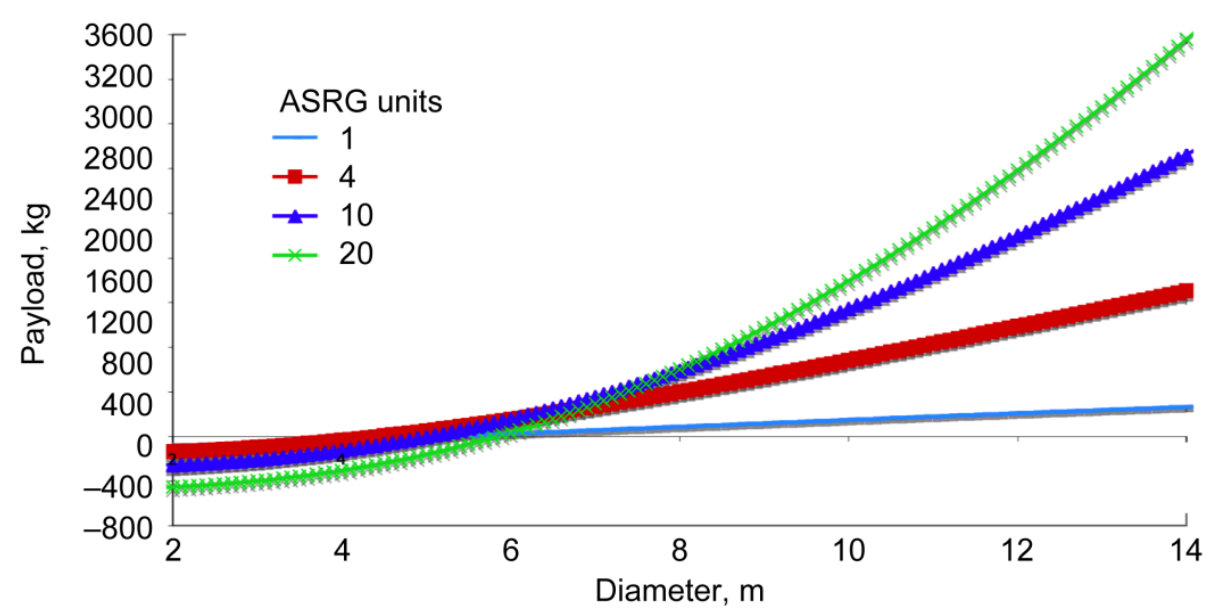

Figure 5.-Effect of the number of ASRG units on the payload mass for different internal diameters with three layers and an insulating gas pocket thickness of $0.05 \mathrm{~m}$.

\section{Effects of the Heat Source on Sizing}

As mentioned previously, an ASRG unit could be substituted for the MMRTG unit used for the calculations in preceding sections, increasing the amount of electrical power produced from a given amount of isotope. Multiple ASRG units could be combined to add additional thermal or electrical power. Each ASRG unit has a mass of about $20 \mathrm{~kg}$ and a thermal output of about $500 \mathrm{~W}$ (Wong 2008). Figure 5 shows the effect that additional ASRG units would have on the resulting payload mass. Increased payload can be achieved by increasing the number of ASRG units used. For example, with an internal diameter of $10 \mathrm{~m}, 20$ ASRG units could support about $1200 \mathrm{~kg}$ of payload more than a single ASRG unit could. However, the additional 19 ASRG units weigh $380 \mathrm{~kg}$. The additional weight would make it much more expensive to launch from Earth. 


\section{Conclusion}

While a hydrogen airship is an inherently simpler design for several missions, the thermal airship is superior for others. Table 3 presents the results of the major design parameters for both the heatedatmosphere airship and a comparable hydrogen airship.

The hydrogen airship has a heavier mass ( 200 kg) compared to the heated-atmosphere airship ( $162 \mathrm{~kg}$ ) in the deployed state. Additionally, the heated-atmosphere airship has a longer possible flight life of up to 154 years compared to 180 days for the hydrogen airship. This was determined by the time it takes the MMRTG unit to decay to the point of neutral buoyancy at the surface, compared to the leak rate for the hydrogen airship. For a desired long-term mission, the heated-atmosphere airship appears better suited. However, for a desired mission under 180 days, the less complex hydrogen airship would likely be a better option.

TABLE 3.-MAJOR BASELINE DESIGN PARAMETER RESULTS

\begin{tabular}{|l|c|c|}
\hline \multicolumn{1}{|c|}{ Parameter } & Heated-atmosphere airship & Hydrogen airship \\
\hline Mass (kg) & 162 & 200 \\
\hline Diameter (m) & 6 & 4.3 \\
\hline Number of layers & 3 & 1 \\
\hline Insulating gas pocket thickness (m) & 0.05 & N/A \\
\hline
\end{tabular}

\section{References}

Colozza, A., Landis, G., and Lyons, V. (2003), “Overview of Innovative Aircraft Power and Propulsion Systems and Their Applications for Planetary Exploration,” NASA/TM—2003-212459, July 2003.

Duffner, J., Liu, M., Mandy, C., Panish, R., and Landis, G.A. (2007), “Conceptual Design of an Airship Mission to Titan,” AIAA Space Conference \& Exposition, Long Beach, California, September 1820, 2007.

Elfes, A., Montgomery, J.F., Hall, J.L., Joshi, S.S., Payne, J., and Bergh, C.F. (2005), “Autonomous Flight Control for a Titan Exploration Aerobot," ${ }^{\text {th }}$ International Symposium on Artificial Intelligence, Robotics and Automation In Space, Munich, Germany, September 5-9, 2005.

Freedman, S., Friedman, J., and Schmieder, J. (1966), "RTG Parametric Study Report for the RTG Study Voyager Task C (U),” JPL Report, JPL-C00458, September 29, 1966.

Friedlander, A.L. (1986), "Buoyant Station Mission Concepts for Titan Exploration,” Acta Astronautica, Vol. 14, pp. 233-242, 1986.

Hall, J.L., Jones, J.A., Kerzhanovich, V.V., Lachenmeier, T., Mahr, P., Pauken, M., Plett, G.A., Smith, L., Van Luvender, M.L., and Yavrouian, A.H. (2008), "Experimental Results for Titan Aerobot Thermo-Mechanical Subsystem Development," Advances in Space Research, Vol. 42, Issue 10, pp. 16411647, November 2008. doi:10.1016/j.asr.2007.02.060.

Jennings, D.E., Nixon, C.A., and Cottini, V. (2011), "Seasonal Changes in Titan’s Surface Temperatures,” Fifth Workshop on Titan Chemistry - Observations, Experiments, Computations, and Modeling, Kauai, Hawaii, 12 April 2011.

Justus, C.G., Duvall, A., and Keller, V.W. (2004), "Engineering-level model atmospheres for Titan and Mars," Proceeds of the International Workshop Planetary Probe Atmospheric Entry and Descent Trajectory Analysis and Science, February 2004.

Lorenz, R.D. (2000a), “Optimizing Science Return from Titan Aerial Explorers,” Aerospace Conference, IEEE, Vol. 7, pp. 493-499, Big Sky, MT, 2000. doi: 10.1109/AERO.2000.879317.

Lorenz, R.D. (2000b), "Post-Cassini Exploration of Titan: Science Rationale and Mission Concepts,” Journal of the British Interplanetary Society, Vol. 53, pp. 218-234, 2000. 
Lorenz, R.D., Lunine, J.I., Zimmerman, W. (2005), "Post-Cassini Exploration of Titan: Science Goals, Instrumentation and Mission Concepts,” Advances in Space Research, Vol. 36, Issue 2, pp. 281285, 2005. doi:10.1016/j.asr.2005.03.080.

Lorenz, R.D., Tokano, T., and Newman, C.E. (2010), "Winds and Tides of Ligeia Mare, With Application to the Drift of the Proposed Time (Titan Mare Explorer) Capsule,” Planetary and Space Science, 2010. doi:10.1016/j.pss.2010.12.009.

“TSSM In Situ Elements,” (2009), ESA Contribution to the Titan Saturn System Mission, ESA-SRE(2008)4, February 12, 2009.

Wong W.A., Wood J.G., and Wilson K. (2008), “Advanced Stirling Convertor (ASC)—From Technology Development to Future Flight Product," Space Technology and Applications International Forum (STAIF-2008), Albuquerque, New Mexico, February 10-14, 2008; NASA/TM-2008-215282.

Wright, H.S., Levine, J.S., Croom, M.A., Edwards, W.C., Qualls, G.D., and Gasbarre, J.F. (2004), "Measurements from an Aerial Vehicle: A New Tool for Planetary Exploration,” Proceedings of SPIE, the International Society for Optical Engineering, Vol. SPIE-5660, No. 23, 2004. 


\begin{tabular}{|c|c|c|c|c|c|}
\hline \multicolumn{5}{|c|}{ REPORT DOCUMENTATION PAGE } & $\begin{array}{l}\text { Form Approved } \\
\text { OMB No. 0704-0188 }\end{array}$ \\
\hline \multicolumn{6}{|c|}{ 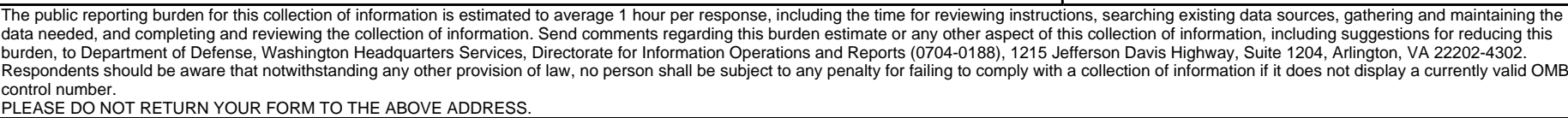 } \\
\hline \multicolumn{2}{|c|}{$\begin{array}{l}\text { 1. REPORT DATE (DD-MM-YYYY) } \\
01-07-2012\end{array}$} & \multicolumn{3}{|c|}{$\begin{array}{l}\text { 2. REPORT TYPE } \\
\text { Technical Memorandum }\end{array}$} & 3. DATES COVERED (From - To) \\
\hline \multirow{3}{*}{\multicolumn{5}{|c|}{$\begin{array}{l}\text { 4. TITLE AND SUBTITLE } \\
\text { Heated-Atmosphere Airship for the Titan Environment: Thermal Analysis }\end{array}$}} & 5a. CONTRACT NUMBER \\
\hline & & & & & 5b. GRANT NUMBER \\
\hline & & & & & 5c. PROGRAM ELEMENT NUMBER \\
\hline \multirow{3}{*}{\multicolumn{5}{|c|}{$\begin{array}{l}\text { 6. AUTHOR(S) } \\
\text { Heller, R., S.; Landis, G., A.; Hepp, A., F.; Colozza, A., J. }\end{array}$}} & 5d. PROJECT NUMBER \\
\hline & & & & & 5e. TASK NUMBER \\
\hline & & & & & $\begin{array}{l}\text { 5f. WORK UNIT NUMBER } \\
\text { WBS 387498.01.03.02.05 }\end{array}$ \\
\hline \multicolumn{5}{|c|}{$\begin{array}{l}\text { 7. PERFORMING ORGANIZATION NAME(S) AND ADDRESS(ES) } \\
\text { National Aeronautics and Space Administration } \\
\text { John H. Glenn Research Center at Lewis Field } \\
\text { Cleveland, Ohio 44135-3191 }\end{array}$} & $\begin{array}{l}\text { 8. PERFORMING ORGANIZATION } \\
\text { REPORT NUMBER } \\
\text { E-18284 }\end{array}$ \\
\hline \multirow{2}{*}{\multicolumn{5}{|c|}{$\begin{array}{l}\text { 9. SPONSORING/MONITORING AGENCY NAME(S) AND ADDRESS(ES) } \\
\text { National Aeronautics and Space Administration } \\
\text { Washington, DC 20546-0001 }\end{array}$}} & $\begin{array}{l}\text { 10. SPONSORING/MONITOR'S } \\
\text { ACRONYM(S) } \\
\text { NASA }\end{array}$ \\
\hline & & & & & $\begin{array}{l}\text { 11. SPONSORING/MONITORING } \\
\text { REPORT NUMBER } \\
\text { NASA/TM-2012-217639 }\end{array}$ \\
\hline \multicolumn{6}{|c|}{$\begin{array}{l}\text { 12. DISTRIBUTION/AVAILABILITY STATEMENT } \\
\text { Unclassified-Unlimited } \\
\text { Subject Categories: } 28 \text { and } 91 \\
\text { Available electronically at http://www.sti.nasa.gov } \\
\text { This publication is available from the NASA Center for AeroSpace Information, 443-757-5802 }\end{array}$} \\
\hline \multicolumn{6}{|c|}{ 13. SUPPLEMENTARY NOTES } \\
\hline \multicolumn{6}{|c|}{$\begin{array}{l}\text { 14. ABSTRACT } \\
\text { Future exploration of Saturn's moon Titan can be carried out by airships. Several lighter-than-atmosphere gas airships and passive drifting } \\
\text { heated-atmosphere balloon designs have been studied, but a heated-atmosphere airship could combine the best characteristics of both. This } \\
\text { work analyses the thermal design of such a heated-atmosphere vehicle, and compares the result with a lighter-than-atmosphere (hydrogen) } \\
\text { airship design. A design tool was created to enable iteration through different design parameters of a heated-atmosphere airship (diameter, } \\
\text { number of layers, and insulating gas pocket thicknesses) and evaluate the feasibility of the resulting airship. A baseline heated-atmosphere } \\
\text { airship was designed to have a diameter of } 6 \mathrm{~m} \text { (outer diameter of } 6.2 \mathrm{~m} \text { ), three-layers of material, and an insulating gas pocket thickness of } \\
0.05 \mathrm{~m} \text { between each layer. The heated-atmosphere airship has a mass of } 161.9 \mathrm{~kg} \text {. A similar mission making use of a hydrogen-filled } \\
\text { airship would require a diameter of } 4.3 \mathrm{~m} \text { and a mass of about } 200 \mathrm{~kg} \text {. For a long-duration mission, the heated-atmosphere airship appears } \\
\text { better suited. However, for a mission lifetime under } 180 \text { days, the less complex hydrogen airship would likely be a better option. }\end{array}$} \\
\hline \multicolumn{6}{|c|}{$\begin{array}{l}\text { 15. SUBJECT TERMS } \\
\text { Titan; Titan atmosphere; Airships; Methane; Hydrogen; In situ resource utilization; Mission planning }\end{array}$} \\
\hline \multicolumn{3}{|c|}{ 16. SECURITY CLASSIFICATION OF: } & $\begin{array}{l}\text { 17. LIMITATION OF } \\
\text { ABSTRACT }\end{array}$ & $\begin{array}{l}\text { 18. NUMBER } \\
\text { OF }\end{array}$ & $\begin{array}{l}\text { 19a. NAME OF RESPONSIBLE PERSON } \\
\text { STI Help Desk (email:help@sti.nasa.gov) }\end{array}$ \\
\hline $\begin{array}{l}\text { a. REPORT } \\
\text { U }\end{array}$ & $\begin{array}{l}\text { b. ABSTRACT } \\
\text { U }\end{array}$ & $\begin{array}{l}\text { c. THIS } \\
\text { PAGE } \\
\text { U }\end{array}$ & UU & $\begin{array}{l}\text { PAGES } \\
14\end{array}$ & $\begin{array}{l}\text { 19b. TELEPHONE NUMBER (include area code) } \\
443-757-5802\end{array}$ \\
\hline
\end{tabular}


